\title{
DINÂMICA DA CENTRAL DE MATERIAL E ESTERILIZAÇĀO: PREPARO DO INSTRUMENTAL UTILIZADO EM CIRURGIAS ORTOPÉTICAS
}

\author{
Domingas Gentil dos Santos * \\ Luzimar Rangel Moreira **
}

\begin{abstract}
RESUMO - Este relato destaca a importância de um Centro de Material com um serviço centralizado e suas vantagens. Comenta a implantação de um sistema de atendimento à programação cirúrgica ortopédica referente ao preparo do instrumental cirúrgico. Relaciona os cuidados importantes a serem observados no uso e manuseio do material, destacando sua manutenção, além de observações a respeito da esterilização do instrumental; contribuindo assim, para o processo ensino/aprendizagem nessa área específica. Conclui-se neste trabalho que a implantação do tal sistema no Hospital Sarah, Brasília, aumentou a produtividade e reduziu os gastos com o material cirúrgico.
\end{abstract}

ABSTRACT - This study shows the importance and the advantages of a Central Supply \& Sterilization System with a centralized service. It demonstrates the implantation of a system that attends the ortopedic surgical program and emphasizes the contribution of this system in the learning and teaching process, showing more production and less material spenditures. It relates the important points to be observed in the use and manipulation of the material, pointing out its maintenance, as well as some notes about sterilizing the instruments.

\section{INTRODUÇĀO}

A Central de Material e Esterilização é o setor que visa o preparo, a esterilização, a estocagem, o controle e a distribuição do material a ser usado em todas as unidades do Hospital.

Este setor pode ser organizado para uma atuação centralizada ou descentralizada. No Hospital de Medicina do Aparelho Locomotor/SARAH, situado em Brasília o sistema centralizado foi adotado por apresentar as seguintes vantagens:

- Concentração do material permanente e de consumo, tornando mais fácil o controle, conservação, manutenção, previsão e provisão dos mesmos;

- Rapidez e eficácia no sistema de atendimento aos setores do Hospital;

- Aumento da produção do material preparado tanto qualitativa quanto quantitativamente;

- Padronização, uniformidade e coordenação das técnicas de limpeza, preparo, empacotàmento e esterilização;
- Facilidade no controle da esterilização, da qualidade do material e equipamento, prolongando a vida útil dos mesmos;

- Facilidade de reserva de material, a fim de atender prontamente às necessidades do Hospital;

- Não duplicação de equipamentos ou instrumentos usados com pouca freqüência;

- Facilidade no treinamento do pessoal para as atividades específicas e afins, trazendo maior produtividade;

- Economia para o Hospital, facilitando o controle do consumo, da qualidade do material e das técnicas de esterilização.

Considerando-se a necessidade de atender satisfatoriamente a demanda, foi implantado um sistema de atendimento à programação cirúrgica onde, com a seleção prévia do instrumental ortopédico específico, visava-se o melhor aproveitamento do trabalho.

A coordenação deste sistema, coube a equi-

* Enfermeira responsável pela Central de Material e Esterilização do HMALSSARAH - Braślia - DF.

* Bnfermeira da Central de Material e Esterilização do HMALSSARAH - Brasflia - DF. 
pe de enfermagem, que através de seus conhecimentos técnicos e presença em todas as etapas do processo assistencial era capaz de exercer a crítica e o controle de qualidade sobre o mesmo.

\section{IMPLANTAÇAO DO SISTEMA}

A implantação do sistema de atendimento à programação cirúrgica pela Central de Material e Esterilização no Hospital de Medicina do Aparelho Locomotor/SARAH, realizada por um grupo de cirurgiões e enfermeiras em julho de 1984, foi coordenada pelo CIRURGIĀO CHEFE DA UNIDADE, Dr. Aloysio Campos da Paz Júnior, e surgiu em função das seguintes constatações:

1) A quantidade de material submetida ao processo de reesterilização era excessiva;

2) Havia desperdício de mão-de-obra no processo do preparo e reesterilização de material que não havia sido utilizado;

3) A quantidade por espécie do instrumental existente era insuficiente para atender a uma demanda não organizada;

4) A média diária das cirurgias ortopédicas era grande, havendo a necessidade de uma atuaçāo dinâmica da Central de Material.

O método utilizado na época constou do agrupamento de instrumentos com finalidades específicas, orientando-se pela própria demanda cirúrgica do Hospital. Assim, para uma osteotornia, foram dispostos os escopros de vários tamanhos e o martelo; para uma osteossítese, as placas. os parafusos e jogos de chaves, etc. Estes instrumentos foram dispostos em mesas e fotografados, construindo-se assim, catálogos fotográficos que mostravam quais os materiais disponíveis, segundo os procedimentos.

Com vistas a atender a programação cirúrgica, os instrumentos selecionados passarem a ser separados, preparados e esterilizados em banclejas ou pacotes na véspera da cirurgia, de acordo com a programação estabelecida. Algumas bandejas de instrumentos básicos, destinadas as vias de acesso aos diversos tipos de cirurgias ortopédicas, devido ao seu uso constante, logo após seu uso continuaram a ser automaticamente preparadas e reesterilizadas.

Paralelamente, os instrumentos que antes permaneciam sempre empacotados e estéreis foram dispostos em cestos, agrupados segundo seu tipo e finalidade, o que permitiu ao cirurgião, na vespéra do procedimento, selecionar aquilo que realmente pretendia utilizar, evitando as desnecessárias reesterilizaçōes que levam ao desgaste do material e ao desperdício da mão-de-obra.

Estabeleceu-se também, um programa de treinamento de enfermeiros, que visava o repas- se das rotinas da seleção e preparo do raterial, com vistas a exercer um melhor controle de qualidade.

Este sistema proporcionou ainda ao cirurgião em treinamento conhecer melhor o material ortopédico específico, de tal forma que podia consultar os catálogos fotográficos, manusear o instrumento e o material de implante dispostos ao seu alcance, e ainda receber das enfermeiras do setor, orientação quanto aos nomes, uso, emprego e a quantidade existente dos diversos instrumentos ali reunidos.

\section{CONTROLE DE QUALIDADE E CONSERVAÇÁO DO INSTRUMENTAL CIRÚRGICO}

A partir da rotina então estabelecida, foi possível instituir um melhor controle sobre a conservação dos instrumentos cirúrgicos, pois estes representam um elevado investimento para os hospitais, necessitando, portanto, de manuseio adequado, tanto durante sua utilização, como na limpeza, acondicionamento e esterilização. $O$ uso inadequado, manuseio rude ou descuido diminuem a vida útil do instrumental.

A maioria dos instrumentos cirúrgicos é de aço inoxidável que é composto de ferro, carbono, cromo e pode contar também com molibdênio, níquel e manganês, entre outros elementos. E o cromo que confere a propriedade inoxidável do aço, permitindo maior resistência à corrosão. C carbono reduz o efeito de resistência à corrosão do cromo, mas é necessário para produzir dureza, condição essencial para determinados instrumentos. As ligas mais apropriadas à fabricação de instrumental cirúrgico contêm baixos teores de cromo e altos de carbono, necessários para permitir têmpera adequada, embora a resistência do aço à corrosão possa ser menor.

Os cuidados que se:ão citados a seguir, levam em consideração a própria composição do aço inoxidável, que requer cuidados especiais:

\section{A - Manusear poucos instrumentos de cada vez}

Não se deve manusear lotes com grande quantidade do instrumental e, conseqüentemente, pesados. Estes, devem ser separados delicadamente em pequenas quantidades, pois os instrumentos que estão embaixo não devem ser pressionados pelo peso dos demais.

\section{B - Abrir todos o.s instrumentos articu-} lados

Os intrumentos com articulação, tais como: tesouras, pinças, porta-agulhas, entre outros, devem ser colocados na bandeja em posição aberta. Os instrumentos maiores, tipo afastadores e instrumentos desmontáveis devem ser desmontados e tratados separadamente. 


\section{C - Pre-lavagem}

Este processo deve ser iniciado o mais rápido possível, para evitar a fixação dos resíduos nos instrumentos.

Tão logo os instrumentos acabem de ser utilizados o funcionário responsável deverá efetuar um banho em água aquecida entre $40^{\circ} \mathrm{e}$ $45^{\circ}$ C. Temperaturas muito elevadas causarão coagulação de proteínas contidas no sangue e nos restos tissulares, e por conseguinte, haverá a fixação na superfície do instrumento dificultando sua remoção.

A imersão completa do instrumental em solução desincrostante, às vezes faz-se necessário, para que haja completa remoção dos resíduos.

\section{D - Lavagem manual}

É o processo mais utilizado para limpeza do instrumental. Consiste no escovamento de peça por peça, sob água morna corrente, onde o sabão neutro é utilizado como detergente. $O$ escovamento deve seguir a direção das serrilhas da pinça, de modo geral transversal e, não longitudinal.

Deve-se evitar o uso de materiais abrasivos, como palhas ou esponjas de aço, pois poderão marcar ou ocasionar microfissuras, favorecendo o processo de corrosão. A escova de nylon é a melhor opção.

Entretanto, deve-se tomar cuidado, pois alguns agentes são agressivos ao aço inox. $\mathrm{O}$ uso de solução na concentração correta, água de preferência morna, a imersão completa do instrumental na solução e a observação do tempo recomendado pelo fabricante do produto, ajudam a minimizar os efeitos indese jáveis dos desiscrostantes sobre a vida útil do instrumental.

\section{E - Lavagem por ultra-som}

Para lavagem dos instrumentos em ultrasom, estes devem ser colocados abertos, com água em temperatura entre $40^{\circ}$ a $45^{\circ}$. $\mathrm{O}$ detergente a ser usado deve ser de $\mathrm{pH}$ neutro e que faça o mínimo possível de espuma.

A água contendo a solução deverá ser observada com freqüência, pois o acúmulo de resíduos pela não renovação da solução comprometerá a eficiência da limpeza.

Os instrumentais mais pesados não poderão ficar sobre os delicados, pois as vibrações poderão causar desgastes prematuros em suas pontas.

Após a limpeza do instrumental por lavagem ultrasónica, deve-se realizar o enxague para a remoção da espuma ou de substancia detergentes.

Enxaguados, os instrumentos devem ser enxutos principalmente nas articulaçōes e encaixes. Deve-se evitar a secagem natural destes, para que os elementos orgânicos ou químicos não se fixem no material.

\section{F - Inspeçāo}

Antes de proceder à esterilização, deve-se realizar uma minuciosa inspeção de cada instrumento. A observação visual deve revelar a completa ausência de qualquer resíduo orgânico ou de outro tipo.

Os instrumentos que apresentam corrosão, ou estejam danificados, deverão ser separados e quando possível encaminhados ao setor de manutenção para recuperação.

\section{4 - REMOMENDAÇŌES IMPORTANTES PARA ESTERILIIZAÇĀO}

Algumas recomendações devem ser observadas para a esterilização de instrumental, de maneira que esta seja perfeita, sem causar danes aos instrumentos, são elas:

1 - Fechar os instrumentos com cremalheiras até o primeiro dente, pois a esterilização e esfriamento provocam a dilatação e a retração no aço, que pode diminuir a elasticidade dos mesmos;

2 - Efetuar lubrificação do instrumental antes da esterilização, caso seja necessário;

3 - Dispor os instrumentos na badeja de forma que não haja impedimento da penetração do vapor e de maneira que os mais pesados fiquem por baixo;

4 - Proteger com gaze, as pontas dos instrumentos cortantes e/ou delicados, para evitar a perfuração dos campos e a danificação dos mesmos durante o manuseio da bandeja, antes do uso;

5 - Envolver a bande ja com o campo de algodão antes de dispor os instrumentos e após a disposição destes, envolvê-los com dois campos de algodão crú, um simples e outro duplo de tamanhos proporcionais ao da badeja;

6 - Amarrar com barbante de algodão as bandejas grandes que comportam materiais pesados, para evitar que estas se abram durante a esterilização e o manuseio;

7 - Rotular com letra legível o nome da cirurgia, data e assinatura de quem preparou, e o nome do paciente e do médico cirurgião, logo após o preparo da bande ja ou pacote;

8 - Evitar a reutilização dos campos após a esterilização sem a devida lavagem, pois neste processo ocorre a dilatação e retração do tecido, levando a diminuição da permeabilidade ao vapor;

9 - Evitar abrir o autoclave prematuramente, pois o choque térmico levará a condensação do vapor no interior da bandeja.

\section{CONCLUSĀO}

A implantação do sistema de atendimento à programação cirúrgica ortopédica da Central de Material do Hospital de Medicina do Aparelho Locomotor/SARAH, proporcionou a racionali- 
zação do trabalho, economia de tempo e recursos materiais e ainda, o treinamento efetivo de recursos humanos, que contribuem de forma concreta para uma boa assistência ao paciente.

Convém ressaltar tamberm, que a qualidade do serviço realizado na Central de Material e
Esterilização, particularmente com relação aos aspectos assistencial, administrativo e econômico, devem ser uma preocupação constante da enfermagem, que através de uma atuação critica e consciente contribuirá decisivamente na redução dos índices de infecção hospitalar.

\section{BIBLIOGRAFIA CONSULTADA}

ASSIS MOURA, M.L.P. Implantação e avaliaçåo de instrumentos de controle em equipamentos e material em Centro Cirúrgico e Central de Material e Esterilização. Enfoque, 6(1): 7-12, 1977.

EDLO. Manual de Conservação de Instrumentos Cirúrgicos. Canoas: EDLO-ZIVI HERCULES, 1987.

GARDES, J.C., TANNER, F. Conditionnement et Stérilization du Matériel Orthopédique Métallique. Rev. Chir. Ortop., 71 (Suppi. II): 55-58, 1984.
JUNQUEIRA, S.M., BIANCHI, E.R.F. Acondicionamento de materiais hospitalares: pontos importantes a serem observados. Enfoque, 15 (1): 11-13, 1986.

LIMA, L.V. Central de Material e seu sistema de distribuição. Enfoque, 8(2): 7-12, 1979.

TAVARES, M.C. Central de Material e Esterilizaçåo em hospitais: pontos a observar e erros a evitar . Rev. Bras. Enf; 32: 230-238, 1979. 